\title{
The Human Rights of Women and Girls with Disabilities: Sterilization and Other Coercive Responses to Menstruation
}

\author{
Linda Steele and Beth Goldblatt
}

\begin{abstract}
INTRODUCTION
Critical menstruation studies scholarship illuminates the politicized nature of menstruation and explores practices of feminist political activism surrounding menstruation (see, for example, Bobel 2010; Winkler and Roaf 2014). Building on the emerging discussions of disability and menstruation in that scholarship (see, for example, Przybylo and Fahs 2018; Winkler and Roaf 2014), in this chapter we introduce some domestic legal and international human rights dimensions of menstruation for women and girls with disabilities. ${ }^{1}$ In particular, we focus on the use of non-consensual sterilization as a coercive response to menstruation. Menstruation is a key site for discrimination and violence against women and girls with disabilities, and on this basis has been the subject of longstanding activism by women with disabilities and their representative organizations (see, for example, Dowse et al. 2013; Ortoleva and Lewis 2012). We argue that it is time for critical menstruation studies scholarship to engage with the legal dimensions of menstruation in relation to women and girls with disabilities, and consider how mainstream menstruation activism can address the experiences and needs of women and girls with disabilities. This argument will be made on two bases. The first is that menstruation by women and girls with disabilities and menstrual behavior purportedly displayed by women and girls with disabilities (for example, poor hygiene management, erratic and emotional behavior, distress at blood) have been the basis for coercive interventions by parents, carers, medical professionals, and the courts, particularly through sterilization. The second is that while international human rights law provides a compelling
\end{abstract}


basis for preventing violence and discrimination related to menstruation, at the domestic level many governments have continued to support measures that enable sterilization and other coercive interventions targeting the menstruation of women and girls with disabilities. Such measures ignore human rights and at times even rationalize these interventions on human rights grounds.

We make our argument by reference to a case study of non-consensual sterilization of women and girls with disabilities in Australia as the most extreme form of coercive intervention, which is at the epicenter of contemporary political debates around reproductive justice for women and girls with disabilities. For example, Women with Disabilities Australia state:

Forced and coerced sterilisation of women and girls with disability is a practice that violates multiple human rights treaties and instruments. It is an act of violence, a form of social control, and a clear and documented violation of the right to be free from torture and ill-treatment. Perpetrators are seldom held accountable and women and girls with disability who have experienced this egregious form of violence are rarely able to obtain any form of redress or justice. $(2016,10)$

While this chapter uses a case study of sterilization, at the outset we note that it is important not to lose sight, in a critical and political sense, of 'less restrictive' alternatives to sterilization, particularly menstrual suppressant drugs. The 'temporary' and 'non-invasive' nature of menstrual suppressant drugs might render them subject to less legal and political scrutiny because they are not viewed as impacting as significantly on bodily integrity and autonomy because they do not involve the surgical cutting of the body, even though they are still non-consensual, involve entry of substances into the body and are similarly underpinned by problematic assumptions about disability, gender, and menstruation (see, for example, McCarthy quoted in Tilley et al. 2012, 422).

We have selected Australia for two reasons. In Australia, non-consensual sterilization of women and girls with disabilities is legal, which is common in many other jurisdictions including New Zealand, Germany, the United States of America, and France (Ortoleva and Lewis 2012, 43-44; Tilley et al. 2012, 415-18). Moreover, the practice and legal status of sterilization of women and girls in Australia have been the subject both of a long-standing campaign by women with disabilities and their representative organizations, and government scrutiny via a series of judicial decisions and parliamentary and law reform inquiries.

The chapter begins with an introduction to a critical framing of disability and menstruation. The chapter then shifts into an introduction to discrimination against women and girls with disabilities and its relationship to menstruation. The third section then discusses the use of sterilization of women and girls with disabilities to manage menstruation. Next, we explain the international human rights approach to disability, menstruation, and sterilization. 
Lastly, we offer Australia as a case study of the challenges at a domestic level of engaging human rights to address issues surrounding menstruation and sterilization.

\section{Disability ANd Menstruation}

Scholars engaged in critical menstruation studies have explored the place of menstruation in women's abjection and marginalization. This is exacerbated for women (including those with disabilities) who are positioned outside of normative constructs of the white, able, middle-class woman (see, for example, Bobel 2010, 28-41; Przybylo and Fahs 2018; Winkler and Roaf 2014, 3-7). An appreciation of these dynamics specifically in relation to women and girls with disabilities can be usefully developed by drawing on critical disability studies scholarship on normalcy.

Some critical disability studies scholars have argued that legal, social welfare, educational, and health service responses to disability can be understood through the lens of a medical model of disability. Pursuant to this medical model, disability is positioned as an individual, biomedical deficit which individualizes and pathologizes the disabled body as the natural target of medical and care interventions. Critical disability studies scholarship contests the medical model and some scholarship proposes that disability should instead be approached as constructed by reference to norms of ability. These norms reflect what is socially, culturally, politically, and economically valued within society, and intersect with norms pertaining to other social hierarchies such as gender, race, and class (Goodley 2014; Michalko and Titchkosky 2009). The medical model is premised on the assumed necessity of therapeutic intervention such that a disabled person's wishes are irrelevant and overridden if therapeutic intervention is considered medically beneficial. Yet, according to some critical disability studies scholarship, non-consensual medical and care interventions ostensibly for the benefit of people with disabilities can be reread as acts of violence directed toward enforcing normative orders and underlying hierarchies (Kafer 2013). For example, in the context of sterilization Tilley et al. state that "after the so-called discrediting of eugenic views associated with Nazism and the holocaust, [sterilization] was reframed on social or therapeutic grounds" (Tilley et al. 2012, 415).

In a context where women are constructed as deficient vis-à-vis men, feminist disability scholars have argued that women and girls with disabilities are positioned against norms of the able woman thus giving rise to greater degrees and different forms of discrimination, violence, and marginalization (Steele and Dowse 2016). Women and girls with disabilities are viewed as mentally and physically incapable of meeting gendered norms to conceal their menstruation (see Wood [Chapter 25] in this volume) and to control their sexuality and manage their fertility. Moreover, in being unable to meet gendered norms of motherhood and sexuality, women and girls with disabilities 
are viewed as burdens on those who provide care to them, with menstruation being seen as an additional and superfluous demand on labor and time for carers because women and girls with disabilities are viewed as not needing menstruation for reproductive reasons (Steele 2014, 23-30). As such, there are assumptions operating on at least three levels: (a) that women and girls with disabilities should conceal and control their menstruation, (b) that women and girls with disabilities are incapable of doing so, and (c) that it is inefficient and unnecessary for others to support women and girls with disabilities to menstruate. Having set out a critical framing for examining menstruation of women and girls with disabilities, we now overlay a legal framing by turning to situate menstruation and disability in the broader context of discrimination and violence against women and girls with disabilities.

\section{Menstruation and Discrimination Against Women and Girls WITH DisABILITIES}

Discrimination may occur directly where, for example, a school refuses to admit a girl with disabilities who cannot manage menstruation unaided. Indirect discrimination could occur where a school does not refuse entry but fails to provide the facilities or supports for girls with disabilities. Here, although there is no policy overtly targeted at excluding menstruating girls with disabilities, the effect is to discriminate against this group. The concept of reasonable accommodation has been developed in discrimination law to require that adjustments are made to ensure the participation of the person who would otherwise be excluded. Disability often deepens individual and household poverty which means that lack of access to resources and facilities including water and sanitary protection can exacerbate discrimination against women and girls with disabilities (House, Mahon, and Cavill 2012, 158). In regions without household water supply, girls with disabilities may face more difficulties in accessing water sources or carrying heavy containers of water (House, Mahon, and Cavill 2012, 154). This means that they experience unequal access to water and sanitation such that they cannot access the personal care that is available to women without disabilities, and hence is a further dimension of the discrimination they experience in relation to menstruation.

Discrimination can be based on and perpetuate stigma and stereotyping. Stigma might result from the decision of a youth group to prevent girls with disabilities from attending excursions while menstruating. The exclusion of menstruating girls with disabilities might not be associated with any particular physical risk presented by the girls, but rather because the visibility of their menstrual blood or their perceived erratic behavior invokes in others feelings of disgust and fear (Steele 2016, 1031). As such, through their exclusion, menstruating girls with disabilities become abjected and dehumanized. Stereotyping would occur, for instance, when a health service provided 
menstrual pain management information to the carer of a woman with disabilities instead of to the woman herself. The service's assumption that the woman would be unable to understand or apply the information is based on stereotypes about people with disabilities lacking capacity or agency which leads to a devaluing of women's rights to dignity, bodily integrity, and reproductive and healthcare choice (Cusack and Cook 2009, 49-55).

Research on women with intellectual disabilities has found that this group experiences difficulties and discrimination in relation to menstruation in a variety of ways (Rodgers 2001; Tilley et al. 2012; Hamilton 2012, Stefánsdóttir 2014). Women may not be given adequate information about menstruation or menstrual management because it is assumed they are incapable of understanding this information. In one study (Rodgers 2001), women with disabilities avoided discussing menstruation with men due to embarrassment and fear that by providing evidence of female bodily functions they might expose themselves to abuse (529-30). They also avoided requesting pain medication from carers, particularly men, and were denied control to self-medicate for menstrual pain (526-27). Embarrassment and fear due to internalized stigma were encountered when women felt they had created a 'mess' or failed to meet perceived menstrual 'etiquette' (530). Their experiences of menstruation were generally negative and disempowering since their bodies were so often subject to control by carers and medical personnel. This assertion of control may result from the discomfort of society with seeing women with disabilities as sexual and as fertile (535).

These forms of discrimination against women and girls with disabilities that arise in relation to menstruation are usually 'intersectional' (Crenshaw 1989). This means that discrimination is not just based on sex/gender or disability alone but emerges from the coming together of both forms of discrimination to create a new type of unequal treatment (Sifris 2016, 55-56). In some cases, the discrimination described above arises from the intersection of one or both of these grounds and a third ground, a woman's menstrual status. The term 'menstrual-status discrimination' has been used by the UN Committee on the Rights of the Child (2016, para. 59e). A person may experience a specific form of discrimination as a menstruating woman with disabilities that a non-menstruating woman with disabilities might not and that a menstruating woman who does not have disabilities would not.

\section{Sterilization, Disability, and Menstruation}

Sterilization is one particularly extreme and severe manifestation of menstrual discrimination against women and girls with disabilities. The effects of sterilization on reproduction and menstruation are permanent. Sterilization procedures which have permanent effects on reproduction and menstruation include hysterectomy, tubal ligation, and endometrial ablation (Australian Senate Community Affairs References Committee 2013, 6). The relationship 
between disability, sterilization, and menstruation is twofold. First, sterilization might be used specifically to prevent menstruation of women and girls with disabilities because of perceived issues with menstruation itself, including its impact on quality of life (for example, ability to participate in education and social events, receive good quality care), behavior (for example, distress and inability to cope with menstruation and 'poor hygiene practices') and existing health conditions (for example, hormonal impacts on epilepsy). Second, sterilization might be used to prevent reproduction and this inadvertently requires preventing menstruation as a key factor in reproductive capacity. Typically, sterilization is rationalized as therapeutic and beneficial, in part because women and girls with disabilities are socially constructed as unable to manage their own menstruation and their menstruation is constructed as redundant and/or posing a threat to themselves or others (Steele 2008).

While there is no comprehensive international survey of laws on sterilization of women and girls with disabilities, in their report on violence against women with disabilities Ortoleva and Lewis cite numerous examples of the legality of sterilization across a number of different countries (43-44; see also Rowlands and Amy 2017). In a variety of countries, non-consensual sterilization of women and girls with disabilities is legal where it is perceived to be in an individual's 'best interests' and occurs following decisions made by a substituted decision-maker (such as a guardian, parent, or court) pursuant to appropriate legal procedure (Ortoleva and Lewis 2012, 41-44). While some countries have more stringent legal tests and judicial safeguards that limit the bases on which sterilization can be authorized (for example, Canada and Germany), even in these jurisdictions laws fall short of complete prohibition of sterilization (Dimopoulos 2016, 163-71; Rowlands and Amy 2017). Moreover, the consistent comments by various United Nations human rights bodies concerning the ongoing human rights violations through sterilization suggest these practices are systemic and widespread and there is yet to be a groundswell of countries absolutely prohibiting sterilization.

The legality of sterilization is concerning because sterilization contravenes fundamental rights related to autonomy, personal integrity, and bodily inviolability. In law, each individual chooses what contact is made with their body. It is a criminal offense and a civil legal wrong if an individual touches another's body without their consent (commonly referred to as assault or battery). This is on the basis that individuals are assumed mentally capable to make decisions about their bodies. In contrast, the law denies this decision-making autonomy to individuals who are considered to lack mental capacity, for example, women and girls with disabilities. Instead, decisions about these women's and girls' bodies made by others such as judges, parents, and guardians are legally relevant in relation to the lawfulness of contact with their bodies. In the context of sterilization, women without disabilities might consent to undertake sterilization perhaps to prevent conceiving children or to mitigate risks of some kinds of cancers. In making these decisions about their 
own bodies, their sterilization will not constitute unlawful contact. In contrast, it is irrelevant whether women and girls with disabilities want to be sterilized (or even know they are to be sterilized) because third parties such as judges, parents, and guardians possess the legal authority to consent to sterilization (Steele 2014). Sterilization in these circumstances is not unlawful and hence is not considered an 'injustice' deserving of redress. The lawfulness of sterilization is of particular concern since in addition to infringement of principles of personal integrity, bodily inviolability, and autonomy, there are multiple harms associated with sterilization including risks and potential side effects associated with surgical procedures, increased risk of some cancers, and ongoing grief and trauma (Australian Senate Community Affairs References Committee 2013, 8; Tilley et al. 2012, 420; Women with Disabilities Australia 2017, 8-9). In addition, sterilization is a totally disproportionate response to menstrual suppression, which in itself should be the choice of the woman herself.

\section{Position Under International Human Rights Law}

International human rights law provides some basis for asserting rights in relation to menstruation for women and girls with disabilities, including preventing sterilization. The rights of women and of people with disabilities are protected under international human rights law through the International Covenant on Civil and Political Rights (ICCPR) and the International Covenant on Economic, Social and Cultural Rights (ICESCR) and in specific conventions protecting the rights of women (the Convention on the Elimination of All Forms of Discrimination against Women, CEDAW) and the rights of people with disabilities (the Convention on the Rights of Persons with Disabilities, CRPD). This section will consider how international human rights law and its interpretation by treaty committees and special mandates holders apply to women and girls with disabilities in relation to menstruation.

Women with disabilities may experience violations that implicate their rights to bodily integrity and their rights to health. Non-consensual sterilization or administering menstrual suppressant drugs would result in a violation of ICCPR Article 7 that states "[n]o one shall be subjected to torture or to cruel, inhuman or degrading treatment or punishment." Forced sterilization of women with disabilities is considered to be cruel and degrading treatment and even torture (UN Special Rapporteur 2017, para. 30). The rights to non-discrimination, dignity, privacy, and the rights of children in the ICCPR would also be affected. At the same time, Article 12 of the ICESCR guarantees "the right of everyone to the enjoyment of the highest attainable standard of physical and mental health." Forced sterilization, as with any surgical procedure, involves dangers to a person's health and violates their right to consent to medical treatment. 
The Special Rapporteur on violence against women, its causes, and consequences has noted that women with disabilities face an "intersecting confluence of violence which reflects both gender-based and disability-based violence" (2011, para. 28) and their marginalization has made them the "target of forced sterilization and other coercive birth control measures" (2011, para. 72). The UN CRPD Committee in its General Comment 3 (2016, para. 29) has noted the increased risk faced by women with disabilities to violence compared to other women. It categorizes such violence as interpersonal or institutional as well as structural that is: based on discrimination directed at a particular group. It gives an example of such violence as "the refusal by caregivers to assist with daily activities such as bathing, menstrual and/or sanitation management . . . which hinders enjoyment of the right to live independently and to freedom from degrading treatment" (para. 31). The Committee on the Elimination of All Forms of Discrimination Against Women understands gender-based violence against women as a form of discrimination (2017) and sees forced sterilization as a form of gender-based violence (para. 18).

The Special Rapporteur on torture and other cruel, inhuman or degrading treatment or punishment has noted that torture can be implied in situations where a person has been discriminated against on the basis of a disability, particularly in the context of a medical procedure (2008, para. 49), including sterilization of women and girls with disabilities (para. 60). The UN CRPD Committee considers forced sterilization to be "cruel, inhuman or degrading treatment or punishment” (2016, para. 32). Different treaty committees have raised concerns with the practice of forced sterilization that is unauthorized and non-therapeutic, for example the Committee on the Rights of Persons with Disabilities in relation to Jordan (CRPD Jordan 2017, paras. 35-36). Many countries have been the subject of recommendations to remove sterilization laws and end sterilization practices targeting women and girls with disabilities, particularly in recent years by the Committee responsible for CEDAW and the UN CRPD Committee including Japan, Kenya, the Czech Republic, Mauritius, Spain, Mexico, and many others (Special Rapporteur 2017, para. 30, footnote 36). The UN CRPD Committee has noted that even in countries where (non-therapeutic) forced sterilization is illegal such as Canada, "people with intellectual and/or psychosocial disabilities still experience involuntary sterilization through the manipulation of their consent" (CRPD Canada 2017, para. 35).

\section{Australia: A Case Study in Menstruation, Sterilization, and Human Rights}

The recent political history of sterilization in Australia illuminates the challenges of engaging human rights in a domestic context in relation to menstruation and disability. Australian women and girls with disabilities and 
their representative organizations have for decades criticized sterilization as a state-sanctioned mode of discrimination, violence, and torture (Frohmader 2013). They have lobbied for its prohibition alongside redress for survivors and greater resources, information and services relating to menstruation, reproduction, and sexuality. In doing so, they have drawn on many of the dimensions of international human rights law discussed above. However, despite these efforts, sterilization of women and girls with disabilities remains lawful in Australia and recent government inquiries have demonstrated little political will to reform.

Sterilization of girls with disabilities is regulated by the Family Court of Australia (FCA). The FCA, operating in its 'welfare jurisdiction,' can authorize parental consent to sterilization of children with intellectual disabilities where the child lacks mental capacity to make decisions, the sterilization is in the 'best interests' of the child and there are no less invasive alternatives (for example, use of menstrual suppressant drugs) that are viable for that individual (for example, because of resistance to taking oral contraceptive) (Secretary, Department of Health and Community Services $v$ JWB ('Marion's Case') (1992) 175 CLR 218). During the 1980s and 1990s, there were a number of FCA decisions and Australian High Court decisions concerning sterilization of girls with disabilities. These decisions illustrate the problematic associations between disability, gender, and menstruation discussed above. They portray girls as risky and dangerous by reason of their leaky bodies and irrational behavior attributed to their menstruation (Steele 2008, 2016). The girls are portrayed as being unable to comprehend menstruation as part of their bodies' processes. For example, in one decision the judge stated: "[during menstruation] L threw herself on the floor and scratched herself on the legs and face, ... she would lash out if someone tried to assist her so they might be injured and she would claw her own body with her fingers until she drew blood" (Re BW (unreported, FamCA, Chisholm J, 10 April 1995) at 10). In this context, sterilization is viewed by judges as being in the girls' best interests because it will protect them from their erratic and risky behavior associated with menstruation and protect them from pregnancy and childbirth, including pregnancy arising from sexual abuse. Judges have also expressed need to use sterilization to avoid the "frightening and unnecessary experience" of being in public with visible bleeding (Re Jane (1988) 12 Fam LR 662 at 681). The judges also approach sterilization as being in the best interests of the child because it will protect parents and carers from the burden of care imposed by their superfluous menstruation and related behavior, and the burden of caring for any child born (Steele 2008). For example, Warnick J described sterilization of Katie as "lessen[ing] the physical burdens for the mother, in particular by decreasing the number of changes necessary in toileting" (Re Katie (unreported, FamCA, Warnick J, 30 November 1995) at 15). Moreover, in some decisions, the Family Court rejected alternatives to menstrual management on the basis that they would not be successful. For 
example, in one decision Cook J dismissed a menstrual management education program because he considered it "difficult to avoid the feeling, that here, perhaps too much reliance is being placed on the success of what are possibly imperfect programs, imperfectly administered and monitored upon, sadly, an imperfect subject" (Re a Teenager (1988) 13 Fam LR 85 at 94). These decisions reflect an institutionalizing of the stereotypes and stigmas associated with disability and menstruation that were introduced above, thus further embedding these as socially, and legally, acceptable and hence more difficult to contest.

In 2013, the Australian Government reported on a Senate Inquiry into sterilization of women and girls with disabilities (Australian Senate Community Affairs References Committee 2013). Menstruation figured prominently in the report, with the Committee noting at the outset that menstrual management is a common reason for sterilization (15). In its report the Committee observed that sterilization was being used to manage a broader array of care issues by reason of "lack of appropriate and adequate support for both people with disabilities and their carers" (31).

Reflecting observations made above about the stereotypes that inform a lack of information about menstruation, sexuality, and reproduction, the Committee also noted difficulty in discussing sexual and reproductive health with women and girls with disabilities to explain to them what was occurring during menstruation and how to manage menstrual hygiene (16). The Committee concluded that "there is a shocking lack of resources available for people with a disability" to assist them with "choices about relationships and sexuality" and "menstrual management" (48). It made a number of recommendations relating to access to education, training and information around sexuality and relationships for people with disabilities and families, medical and disability workers (ix), and about disability support planning addressing support for menstruation as well as 'support for relationships and sex education' (ix). Certainly, this is an improvement of the current position insofar as there is explicit recognition of educating women and girls with disabilities and their associates on menstruation. Yet, the report ultimately fell short of recommending that sterilization should not be permitted.

As part of its inquiry, the Committee was specifically tasked with considering Australia's compliance with its international obligations. Ultimately, the Committee was of the view that Australia's international human rights obligations did not require the prohibition of sterilization and sterilization could continue but recommended reforming the legal test from 'best interests' to 'best protection of rights.' This proposed test focuses on particular human rights, for example, to health and inclusion, and excludes the fundamental right of non-discrimination and equality. As such, it would be open for interpretations that are based on discriminatory ideas about disability (Steele $2016,1004,1036)$. It is troubling that sterilization has been affirmed as an 
appropriate intervention even in the face of the explicit attention to human rights of women and girls with disabilities in the CRPD.

In its review of Australia, in 2013, the UN CRPD Committee stated it was "deeply concerned that the Senate inquiry report . . . puts forward recommendations that would allow this practice to continue" (Committee on the Rights of Persons with Disabilities 2013, 5 [39]). The Committee urged Australia to adopt laws prohibiting sterilization "in the absence of their prior, fully informed and free consent" (6 [40]).

The resilience of discriminatory approaches to menstruating women and girls with disabilities, despite tireless efforts by advocates over many years, points to the persistence of stereotypes, power inequities, and limited recognition of the voices of women and girls with disabilities. Continued struggle is required, and critical menstruation scholars and activists could be useful allies.

\section{Conclusions}

This chapter has introduced some of the political and legal dynamics around menstruation facing women and girls with disabilities. We have argued that for women and girls with disabilities menstruation cannot be understood as an individual medical issue. Instead, menstruation needs to be understood in broader social and political contexts with consideration to the cultural and material dynamics that position women and girls with disabilities as not entitled to menstruate and, in turn, render menstruation a basis for discrimination and violence against women and girls with disabilities. The Australian case study has highlighted the endurance of cultural ideas about disability and menstruation in law, and the material impacts this has on women and girls with disabilities through violent, discriminatory and harmful practices of sterilization, as well as the resilience of these cultural ideas in the face of progressive human rights. Human rights violations relating to disability and menstruation track onto a broader longstanding problem of governments regularly violating human rights of people with disabilities and other marginalized groups. This arises from the limited enforceability of international human rights law in that governments, in exercising their state sovereignty, choose whether and how to meet their treaty obligations. Despite this problem, the capacity for international human rights law to frame sterilization as an issue of violence and discrimination and to foreground the equality and personal integrity of women and girls with disabilities provides a powerful ethical and moral force for challenging social assumptions about the inevitability of inequality of women and girls with disabilities (including in the context of menstruation) and the presumed therapeutic necessity of sterilization. In this way, international human rights law can be a vehicle for garnering widespread public support for domestic law reform on issues relating to menstruation and sterilization. Domestic law reform measures should 
be transformative in ensuring that structural change results for women and girls with disabilities (Fredman and Goldblatt 2014), addressing the systemic social, economic, and cultural issues that sustain the legitimacy and necessity of menstrual discrimination and violence.

Our chapter provides openings for critical menstruation scholars and activists to engage with ways in which domestic law and international human rights law might recognize menstrual injustice and menstrual harms and how these might be adequately redressed to ensure individual and transformative justice. Recalling that women and girls with disabilities are culturally and legally positioned as not meeting normative female gender roles, future engagement by critical menstruation studies scholars and menstrual activists should also consider how the situation of women and girls with disabilities relates to broader political issues around menstrual discrimination such as tampon taxes (see Weiss-Wolf [Chapter 41] in this volume) and menstrual leave (see Levitt and Barnack-Tavlaris [Chapter 43] in this volume) which are not necessarily of prime importance to women and girls with disabilities who are instead confronted with the possibility of removal of their very ability to menstruate per se. Therefore, such campaigns should not assume that all women are affected in the same way and should also address the diverse needs of women as well as trans men, intersex people, and others that experience discrimination in relation to menstruation (Goldblatt and Steele 2019).

\section{Note}

1. Przybylo and Fahs note that menstruation is 'complex: it is both highly gendered and not attached as a material reality to only one gender' (Przybylo and Fahs 2018,209 ). We recognize that people who menstruate and are trans, intersex or gender non-conforming experience particular forms of discrimination and that addressing the full scope of menstruation discrimination goes beyond discrimination against women. In this article, however, we focus only on the legal dimensions relating to cisgender women and girls with disabilities.

\section{REFERENCES}

Australian Senate Community Affairs References Committee. 2013. Inquiry into Involuntary or Coerced Sterilisation of People with Disabilities in Australia. Canberra: Commonwealth of Australia.

Bobel, Chris. 2010. New Blood: Third-Wave Feminism and the Politics of Menstruation. New Brunswick: Rutgers University Press.

Crenshaw, Kimberle. 1989. "Demarginalizing the Intersection of Race and Sex: A Black Feminist Critique of Antidiscrimination Doctrine, Feminist Theory and Antiracist Politics." University of Chicago Legal Forum 140: 139-67.

Cusack, Simone, and Rebecca J. Cook. 2009. "Stereotyping Women in the Health Sector: Lessons From CEDAW." Washington \& Lee Journal Civil Rights \& Social Justice 16: 47-78. http://scholarlycommons.law.wlu.edu/crsj/voll6/iss1/5/. 
Dimopoulos, Andreas. 2016. Issues in Human Rights Protection of Intellectually Disabled Persons. London and New York: Routledge.

Disabled People's Organisation's Australia. 2017. Submission to the Committee on the Rights of Persons with Disabilities List of Issues [Australia] to Be Adopted during the 18th Session of the Committee on the Rights of Persons with Disabilities. Prepared by Women with Disabilities Australia (WWDA) on behalf of DPO Australia. Sydney: Disabled People's Organisations Australia (DPO Australia).

Dowse, Leanne, Karen Soldatic, Aminath Didi, Carolyn Frohmader, and Georgia van Toorn. 2013. Stop the Violence: Addressing Violence Against Women and Girls with Disabilities in Australia: Background Paper. Hobart: Women with Disabilities Australia. http://www.stvp.org.au/National-Symposium.htm.

Fredman, Sandra, and Beth Goldblatt. 2014. Gender Equality and Human Rights. Discussion Paper for Progress of the World's Women 2015. New York: UN Women, 1-60.

Frohmader, Carolyn. 2013. Women with Disabilities Australia, Submission No. 49 to Senate Community Affairs References Committee, Parliament of Australia. Inquiry into Involuntary or Coerced Sterilisation of People with Disabilities in Australia, March 2013. https://www.aph.gov.au/DocumentStore. ashx?id=0406ad6a-c555-47f2-8e3d-60a7cf8a04ld\&subId=16161.

Goldblatt, Beth, and Linda Steele. 2019. "Bloody Unfair: Inequality Related to Menstruation - Considering the Role of Discrimination Law." Sydney Law Review 41 (3): 293-325. http://classic.austlii.edu.au/au/journals/SydLawRw/2019/13. html.

Goodley, Dan. 2014. Dis/Ability Studies: Theorising Disablism and Ableism. London and New York: Routledge.

Hamilton, C. 2012. "Sterilisation and Intellectually Disabled People in New Zealand-Still on the Agenda?" Ko-tuitui: New Zealand Journal of Social Sciences Online 7, no. 2 (November): 61-71. https://doi.org/10.1080/11770 83X.2012.724693.

House, Sarah, Thérèse Mahon, and Sue Cavill. 2012. Menstrual Hygiene Matters: A Resource for Improving Menstrual Hygiene around the World. Water Aid. https:// washmatters.wateraid.org/publications/menstrual-hygiene-matters.

Kafer, Alison. 2013. Feminist, Queer, Crip. Bloomington: Indiana University Press.

Michalko, Rod, and Tanya Titchkosky. 2009. "What Is and What Is Not Disability Studies." In Rethinking Normalcy: A Disability Studies Reader, edited by Rod Michalko and Tanya Titchkosky, 1-14. Toronto: Canadian Scholars Press.

Ortoleva, Stephanie, and Hope Lewis. 2012. Forgotten Sisters: A Report on Violence Against Women with Disabilities, An Overview of Its Nature, Scope, Causes and Consequences. Women Enabled and Northeastern University School of Law. https://womenenabled.org/pdfs/Ortoleva\%20Stephanie\%2 $\% 20$ Lewis\%20 Hope\%2 0et\% 20al\%2 0Forgotten\%2 0Sisters\%2 0-\%20A\%20Report\%20on\%20 ViolenceAgainst $\% 20$ Women\%20\%20Girls\%20with\%20Disabilities\%20August $\% 20$ 20\%202012.pdf.

Przybylo, Ela, and Breanne Fahs. 2018. "Feels and Flows: On the Realness of Menstrual Pain and Cripping Menstrual Chronicity." Feminist Formations 30 (1): 206-29.

Rodgers, Jackie. 2001. "Pain, Shame, Blood and Doctors: How Women with Learning Difficulties Experience Menstruation." Women's Studies International Forum 24 (5): 523-39. https://www.sciencedirect.com/science/article/abs/pii/ S0277539501001959. 
Rowlands, Sam, and Jean-Jacques Amy. 2017. "Sterilization of Those with Intellectual Disability: Evolution from Non-Consensual Interventions to Strict Safeguards." Journal of Intellectual Disability, forthcoming, online first. https://doi. org/10.1177/1744629517747162.

Sifris, Ronli. 2016. “The Involuntary Sterilisation of Marginalised Women: Power, Discrimination, and Intersectionality." Griffith Law Review 25 (1): 45-70.

Steele, Linda. 2008. "Making Sense of the Family Court's Decisions on the Non-Therapeutic Sterilisation of Girls with Intellectual Disability." Australian Journal of Family Law 22 (1): 1-23.

- 2014. "Disability, Abnormality and Criminal Law: Sterilisation as Lawful and Good Violence." Griffith Law Review 23 (3): 467-97.

- 2016. "Court-Authorised Sterilisation and Human Rights: Inequality, Discrimination and Violence Against Women and Girls with Disability?" UNSW Law Journal 39 (3): 1002-37. http://www.unswlawjournal.unsw.edu.au/sites/ default/files/393-4.pdf.

Steele, Linda, and Leanne Dowse. 2016. "Gender, Disability Rights and Violence Against Medical Bodies." Australian Feminist Studies 31 (88): 117-24.

Stefánsdóttir, Guđrún V. 2014. "Sterilisation and Women with Intellectual Disability in Iceland." Journal of Intellectual \& Developmental Disability 39 (2): 188-97.

Tilley, Elizabeth, Jan Walmsley, Sarah Earle, and Dorothy Atkinson. 2012. "The Silence is Roaring': Sterilization, Reproductive Rights and Women with Intellectual Disabilities." Disability \& Society 27 (3): 413-26.

Winkler, Inga, and Virginia Roaf. 2014. "Taking the Bloody Linen Out of the Closet: Menstrual Hygiene as a Priority for Achieving Gender Equality." Cardozo Journal of Law and Gender 21 (1): 1-37.

Women with Disabilities Australia (WWDA) Position Statement 4: Sexual and Reproductive Rights. WWDA, September 2016, Hobart, Tasmania.

\section{Human Rights Documents}

The Committee on the Elimination of All Forms of Discrimination Against Women. 2017. General Recommendation No. 35 on Gender-Based Violence Against Women, Updating General Recommendation No. 19, CEDAW/C/GC/35.

Committee on the Rights of Persons with Disabilities (CRPD). 2017. Concluding Observations on the Initial Report of Jordan, CRPD/C/JOR/CO/1.

Committee on the Rights of Persons with Disabilities (CRPD). 2017. Concluding Observations on the Initial Report of Canada, CRPD/C/CAN/CO/1.

Committee on the Rights of Persons with Disabilities (CRPD). 2013. Concluding Observations on the Initial Report of Australia, Adopted by the Committee at Its Tenth Session (2-13 September 2013), 21 October, UN Doc CRPD/C/AUS/ $\mathrm{CO} / 1$.

The Committee on the Rights of Persons with Disabilities. 2016. General Comment No. 3 (2016) on Women and Girls with Disabilities, CRPD/C/GC/3.

Committee on the Rights of the Child. 2016. Concluding Observations: Nepal, $\mathrm{CRC} / \mathrm{C} / \mathrm{NPL} / \mathrm{CO} / 3-5$. 
United Nations Special Rapporteur on Torture and Other Cruel, Inhuman or Degrading Treatment or Punishment. 2008. Report to the General Assembly, A $/ 63 / 175$.

United Nations Special Rapporteur on Violence Against Women, Its Causes and Consequences. 2011. Report to the Human Rights Council, A/HRC/17/26.

United Nations Special Rapporteur on the Rights of Persons with Disabilities. 2017. Sexual and Reproductive Health and Rights of Girls and Young Women with Disabilities, Report to the Human Rights Council, A/72/133.

Open Access This chapter is licensed under the terms of the Creative Commons Attribution 4.0 International License (http://creativecommons.org/licenses/ by $/ 4.0 /$ ), which permits use, sharing, adaptation, distribution and reproduction in any medium or format, as long as you give appropriate credit to the original author(s) and the source, provide a link to the Creative Commons license and indicate if changes were made.

The images or other third party material in this chapter are included in the chapter's Creative Commons license, unless indicated otherwise in a credit line to the material. If material is not included in the chapter's Creative Commons license and your intended use is not permitted by statutory regulation or exceeds the permitted use, you will need to obtain permission directly from the copyright holder.

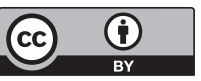

